\title{
A STUDY OF RELATIONSHIP OF COGNITIVE STYLES WITH STUDENTS' ACADEMIC ACHIEVEMENT IN THE SUBJECT OF SCIENCE AT ELEMENTARY LEVEL
}

\author{
By \\ Shagufta Akhtar \\ Manzoor Arif ${ }^{\circ \bullet}$
}

\begin{abstract}
This paper aimed at investigating the relationship of cognitive styles with students' academic achievement in the subject of science at elementary level. A sample of 511 students, studying in $8^{\text {th }}$ class, was taken from five Pakistani public sector secondary schools. The data collected through the study instruments were analyzed by using Pearson product moment correlation, partial correlation and $t$ test. Results indicate that male students tended to be more field dependent, while female students were more inclined towards field independence and the low achievers were found to be field dependent while high achievers tended to be field independent. Results have many implications for teachers, e.g. teachers may help field dependent children act more field independently to achieve well in those subject areas where field independence is required.
\end{abstract}

Key words: Cognitive Styles, Field Dependence - Independence, Academic Achievement and Cognitive Styles, Group Embedded Figures Test.

\section{Introduction}

Research studies in the field of cognitive psychology have indicated that children all over the world exhibit significant individual differences in the cognitive processing styles which they utilize in problem solving and other cognitive activities. Findings of these research studies have pointed out various dimensions of individual differences (Riding and Cheema, 1991). Among these dimensions, cognitive/learning style is an important one, which affects learning. Age, aptitude, general intelligence, modality preferences (e.g. visual, auditory, and kinesthetic), motivation and socio cultural factors are other important variables in this respect.

The notion of cognitive styles is fairly new. It grew out of research on how people perceive and organize information received from their environment and is based on the belief that children all over the world have their own individual styles of perceiving, remembering and thinking. In other words, they have distinctive ways of taking in, storing, transforming, utilizing information and solving various problems.

A number of cognitive styles have been identified by the psychologists and studied over the years, but most of the psychologists (Woolfolk, 2004; Ormrod, 1998; Crowl, 1997; Dembo,

\footnotetext{
- The writer is a Ph.D scholar in AIOU, Islamabad.

- The writer is working as Professor, University of Arid Agricultural, Rawalpindi.
} 
1994; and Child, 1993) have explained three well known types of cognitive styles, i.e. Field Dependent versus Field Independent, Impulsivity versus Reflection and Holist versus Serialist.

The present study focused on only one dimension, i.e. Field Dependence- Independence. Woolfolk (2004) describes field dependent-independent people in the following words:

People who are field dependent tend to perceive a pattern as a whole, not separating one element from the total visual field. They have difficulty in focusing on one aspect of situation, picking out important details, analyzing a pattern into different parts, or monitoring their use of strategies to solve problems. They tend to work well in groups, have a good memory for social information, and prefer subjects such as literature and history. Field-independent people, on the other hand, are more likely to monitor their own information processing. They perceive separate parts of a total pattern and are able to analyze a pattern according to its components. They tend to perform better when working in unstructured situations and are not as attuned to social relationships as field-dependent people, but they do well in math and science, where their analytical abilities pay off. (p. 119)

Some other researchers (Acharya 2002, Musser 1998, Mariani 1996, Hansen 1995, Vasquez 1991) have highlighted that field dependence-independence and learning have some relationship. For instance, field independent learners are intrinsically motivated to learn something, enjoy individualized learning and have the capability of restructuring their knowledge. They prefer inductive learning. Abstr action is easier for them. They are not influenced by the environment rather inclined to be task oriented and are strongly influenced by their own judgments. Field dependent learners, on the other hand, are sensitive to their environment, need extrinsic motivation to learn. They are group-oriented, strong in interpersonal relationships, enjoy cooperative learning, and require greater structure and clarity to perform well and to process their experiences. They prefer deductive learning and integration is easier for them.

Research studies conducted on the cognitive/ learning styles conclude that cognitive styles are one of the most important determinants of the individual's educational attainment. For example, Altun and Cakan (2006) are of the view that cognitive style is an important factor that can affect students' academic achievement on various school subjects. These research studies have produced findings indicating significant differences in academic achievement by students manifesting different cognitive/learning styles. According to Hansen (1995), "students with equal learning abilities but different cognitive styles may experience different levels of success in the same environment": (Discussion section) In addition, Liu and Ginther (1999) have also pointed out that "cognitive styles can have both positive and negative relationships with motivation and academic achievement, but it depends on the nature of the learning task". (Introduction section)

Therefore, it can be said that before starting teaching to the students, a teacher has to respond to the cognitive style needs of students, which requires the teacher to get knowledge of students' preferences and make conscious efforts to expand his/her range of techniques to respond to student diversity. Mariani (1996) is of the view that understanding of students' cognitive and learning styles helps teachers understand their own teaching styles. Irvine and 
York (1995) also argue that a student's learning style, if accommodated, can result in improved attitudes toward learning and an increase in thinking skills, academic achievement, and creativity.

The amount of research and awareness about the relationship between teaching and cognitive styles has increased around the world due to recognition of its importance. Researchers have explored cognitive/learning styles in-depth and have come up with valuable outcomes. These outcomes are incorporated in the field of education at a larger scale and student researchers are benefiting from it immensely. This area of research was selected for the present study, since educators in Pakistan are less aware of these research developments and much research has not yet been carried out in this field.

Literature on cognitive/learning styles indicates that students' cognitive styles have not only relationship with teaching style, but are also affected by many other variables like gender, culture, socio-economic status and academic achievement. But, in Pakistan, no studies so far have been carried out on the relationship of cognitive styles with these or any other equally important variables. Keeping this in mind, the present study investigates the relationship of cognitive styles (field dependence and field independence) with students' academic achievement in the subject of science at elementary level.

The findings of present study will generate indigenous knowledge on children studying in Pakistani secondary schools which will enable teachers to expand their range of techniques to respond to student diversity and to accommodate or modify their cognitive styles, resulting in improved learning and thinking skills, academic achievement and creativity.

The study may also reveal some connection or otherwise between the cognitive style and achievement in the subject of science, as it is indicated in the literature that field independent persons tend to be attracted in science and mathematics. Therefore, they are more likely to perform better in these subjects than the field dependents. So the knowledge of such relationship may help teachers to guide their students in the selection of subjects at secondary level.

The objectives of the study included identifying the cognitive styles (field dependence and field independence) of elementary level students, exploring the relationship between cognitive styles and academic achievement of the students in the subject of science at elementary level, and suggesting teaching implications on the basis of findings of the study.

In order to achieve the objectives of the study, two null hypotheses were formulated. The first hypothesis was that there is no significant correlation between cognitive style scores and academic achievement scores after partialing out the influence of scholastic aptitude, study hours, age, gender and social class, while the second hypothesis was that there is no significant difference between the mean cognitive style scores of low achievers and high achievers.

The study was delimited to the government secondary schools located in Rawalpindi and Bahawalpur districts of the Punjab province in Pakistan, Urdu medium students of $8^{\text {th }}$ class, the subject of Science, and the cognitive style of Field Dependence-Independence. 


\section{Method and Procedure}

The present study was correlational in nature. Population of the study comprised all the children studying in class eighth in public sector secondary schools located in the districts of Rawalpindi and Bahawalpur in Punjab province (Pakistan). The sample of study consisted of 511 students, studying in class eight in public sector secondary schools located in the districts of Rawalpindi and Bahawalpur.

Two stage cluster sampling technique was used to select the sample of the study. At the first stage, five public sector secondary schools, out of 611 schools, were randomly selected from both the districts of Rawalpindi and Bahawalpur. At the second stage, 511 students, out of 55,900 students, from all five sample schools were selected randomly. The total number of students taken from each school is given below:

\section{Sampling Frame}

\begin{tabular}{cccccc}
\hline District & Male Schools & Male Sample & Female Schools & Female Sample & Total \\
& & & & & \\
\hline Rawalpindi & 2 & 129 & 1 & 127 & 256 \\
Bahawalpur & 1 & 126 & 1 & 129 & 255 \\
\hline Total & $\mathbf{3}$ & $\mathbf{2 5 5}$ & $\mathbf{2}$ & $\mathbf{2 5 6}$ & $\mathbf{5 1 1}$ \\
\hline
\end{tabular}

\section{Instruments of the Study}

The cognitive styles of the students were identified with the help of the Group Embedded Figures Test (GEFT) prepared by Oltman, Raskin and Witkin (1971).

The academic achievement of the sample students was determined by averaging out the marks obtained in the subject of science in the previously held examination at school (ascertained from the school record) and the scores obtained in the academic achievement test in the subject of science, specifically designed for the sample students. The test was developed to check the first three levels of Cognitive Domain as suggested by Bloom in his taxonomy: knowledge, comprehension and application.

In order to partial out the influence of scholastic aptitude of the students, study hours allocated to the subject of science per day, and social class of the students, three more instruments were used, i.e. the Scholastic Aptitude Test No.2 (University of the Punjab, Lahore, 1971), Study Hours Questionnaire prepared by the researcher, and Section A of the Socio Economic Scale for Pakistan Version 2.1 (Mumford and Mohsina Mirza, 2001). Parental education and parental occupations were also taken into account for the determination of the social class. Ages of the sample students were taken from the school record for the purpose of partial correlation.

All the instruments of the study were pretested on a small sample of 20 students, taken from the population of the study. The instruments were found to be valid and reliable for the sample of the study. The GEFT is the most appropriate, reliable, and valid instrument to check the dimension of field dependence-independence and was used in many studies e.g. Lu and Suen (1995), Hansen (1995), Efiong (n.d.), (1993), Safdar (2002) and Altun and Cakan (2006). The reliability of GEFT was also calculated after administering it on Pakistani children, by using the 
split half reliability technique and by applying Spearman Brown Prophecy Formula (Garrett, 2000, p. 339). The reliability coefficient of GEFT was 0.73 .

Reliability of the academic achievement test in the subject of science was determined with the help of split half reliability technique. Value of $\boldsymbol{r}$ was 0.6 which is acceptable for a nonstandardized class room test because classroom tests do not need exceptionally high reliability coefficient (Runder and Schafer 2000, Kubiszyn and Borich 2003, Wells and Wollack n.d.).

\title{
Scoring of the Data
}

To score GEFT, the exact procedure set out in the technical manual of GEFT (Witkin, et al., 1971, p.28) was closely followed. The score was the total number of simple forms correctly traced in Second and Third Sections combined. Omitted items were scored as incorrect. The items in the First Section were not included in the total score because this section was primarily for practice. The maximum score for the GEFT was 18.

A scoring key was used to score the items of GEFT. The scoring key was provided in the technical Manual with the Simple Form traced over each Complex Figure. In order to receive credit for an item, all lines of the Simple Form were to be traced including the inner lines, where applicable. It was also important to make sure that no extra lines were added by the subject and that all incorrect lines were erased. Since Witkin et al. (1971) do not specify a clear cut off score for determining field dependent and independent individuals, the median was used to identify the cognitive style of elementary level students in the present study. The students, who obtained less than the median score in GEFT, were considered as "field dependent" because their scores indicated that they were unable to identify embedded figures correctly. Whereas, the students, whose GEFT scores were above median, were identified as "field independent".

The academic achievement test in the subject of science consisted of 40 multiple choice questions, each having four options. The students were required to encircle the correct answer. To score the academic achievement test, each correct response was scored as ' 1 ' and wrong answer as ' 0 '. No negative marking was done in the test. The maximum score was 40.

\section{Analysis of the Data}

The data collected through study instruments were summarized by calculating mean score and standard deviation score on each variable of the study. To test hypothesis 1, the correlation between cognitive style scores and academic achievement scores of the students was computed through Pearson Product Moment Correlation. The exact correlation value between these two variables was determined by using partial correlation technique. In order to test hypothesis $2, \boldsymbol{t}$ test was applied.

Significance of the coefficient of correlation was checked at 0.05 level for the nearest degree of freedom $(\mathrm{df})$. The Probable Error of relationship $\left(\mathrm{PE}_{\mathrm{r}}\right)$ was calculated to interpret the correlation coefficient in terms of degree of relationship.

\author{
Results \\ Table - 1 \\ Summary of Raw Scores on Study Variables $(\mathrm{N}=511)$
}




\begin{tabular}{lccccc}
\hline \multicolumn{1}{c}{ Category } & $\begin{array}{c}\text { Maximum } \\
\text { Score }\end{array}$ & Range & Median & Mean & SD \\
\hline Cognitive Style & 18 & $0-18$ & 4.00 & 5.15 & 4.25 \\
Academic Achievement & 40 & $7-36$ & 20.00 & 20.68 & 5.32 \\
Scholastic Aptitude & 66 & $9-58$ & 31.00 & 30.59 & 9.01 \\
Study Hours & 160 & $0-160$ & 60.00 & 58.03 & 29.93 \\
Social Class & 36 & $5-29$ & 15.00 & 15.56 & 4.78 \\
\hline
\end{tabular}

Table 1 indicates the summary of raw scores on study variables.

Table - 2

Cognitive Styles of Elementary Level Students ( $\mathbf{N = 5 1 1 )}$

\begin{tabular}{cccccc}
\hline Category & N & $\begin{array}{c}\text { Field } \\
\text { Dependent }\end{array}$ & \multicolumn{3}{c}{$\begin{array}{c}\text { Field } \\
\text { Independent }\end{array}$} \\
\hline & & No. & \% & No. & \% \\
\cline { 3 - 6 } Male Students & 255 & 132 & 51.76 & 123 & 48.24 \\
Female Students & 256 & 94 & 36.72 & 162 & 63.28 \\
\hline
\end{tabular}

Table 2 presents the cognitive styles of elementary level students. Male students tended to be more field dependent, while female students were more inclined towards field independence.

Table -3

Cognitive Styles of Low Achievers and High Achievers ( $N=511$ )

\begin{tabular}{cccccc}
\hline Category & N & $\begin{array}{c}\text { Field } \\
\text { Dependent }\end{array}$ & & $\begin{array}{c}\text { Field } \\
\text { Independent }\end{array}$ & \\
\hline & & No. & \% & No. & $\%$ \\
\cline { 3 - 6 } Low Achievers & 242 & 127 & 52.47 & 115 & 47.52 \\
High Achievers & 269 & 99 & 36.80 & 170 & 63.19 \\
\hline
\end{tabular}

It may be concluded from the figures presented in table 3 that majority of low achievers in the subject of science appeared to be field dependent. On the other hand, quite large number of high achievers was found to be field independent in their cognitive style, which indicates that field independence increases with the increase in academic achievement.

Table -4

Significance of Relationship between Cognitive Styles Scores and Academic Achievement Scores ( $N=511)$

\begin{tabular}{ccc}
\hline $\mathrm{R}$ & $\mathrm{PE}_{\mathrm{r}}$ & Degree of Relationship \\
\hline 0.13 & .03 & Some Relationship \\
\hline
\end{tabular}

Figures in table 4 show that correlation coefficient between cognitive style and academic achievement, after partialing out the influence of scholastic aptitude, study hours, age, social 
class and gender, is 0.13 . The probable error in this correlation is 0.03 . As the value of correlation is more than four times of the probable error, according to Garrett (2006, p. 170), some relationship exists between cognitive style scores and academic achievement scores. The first null hypothesis is, therefore, rejected.

The interpretation of above table leads us to the conclusion that some relationship exists between the cognitive style and academic achievement of elementary level students. This relationship can be considered as exact relationship between the two variables because it was calculated by keeping the influence of scholastic aptitude, study hours, age, social class and gender constant. Table 5 below indicates the gradual decrease in the value of correlation coefficient as a result of partialing out the influencing variables. In case of simple correlation between cognitive styles and academic achievement, the value was as high as 0.35 , which decreased, after applying partial correlation technique, to 0.13 .

Table -5

Correlation between Cognitive Styles and Academic Achievement Subsequent to Gradual Partialing out Factors Influencing Academic Achievement

\begin{tabular}{lc}
\hline \multicolumn{1}{c}{ Variables } & Value of $\boldsymbol{r}$ \\
\hline Without partialing out any variable & 0.35 \\
After partialing out: & \\
Scholastic Aptitude and Study Hours & 0.142 \\
Age & 0.140 \\
Social Class & 0.138 \\
Gender & 0.13 \\
\hline
\end{tabular}

Table -6

Difference between Mean Cognitive Style Scores of Low Achievers and High Achievers $(\mathrm{N}=\mathbf{5 1 1})$

\begin{tabular}{cccccc}
\hline Category & Mean & SD & SE $_{\text {diff }}$ & $\boldsymbol{t}$ value & P \\
\hline Low Achievers & 3.92 & 3.34 & & & \\
High Achievers & 6.26 & 4.66 & 0.36 & 6.44 & 0.00 \\
\hline $\mathrm{df}=509$ & & $t_{.05}=1.96$ &
\end{tabular}

Entries given in table 6 show that difference between the mean cognitive style scores of low achievers and high achievers is 2.34 which is highly significant because the obtained $t$ value 6.44 is much higher than the critical $t$ value at .05 level of significance and is also significant at 0.00 level. The second null hypothesis is, therefore, rejected.

As indicated in the above table, the mean cognitive style score of high achievers is higher than the mean cognitive style score of low achievers. It is, therefore, concluded that the cognitive style scores of low achievers and high achievers are different from each other. 


\section{Discussion}

The present study was an attempt to explore the relationship of cognitive styles with students' academic achievement in the subject of science at elementary level. Results indicate that relationship exists between these two study variables. The low achievers were found to be field dependents while the high achievers tended to be field independent. The relationship between these two variables was calculated by keeping the influence of such variables as scholastic aptitude, study hours, age, social class and gender, constant in order to get accurate results regarding relationship of cognitive styles with academic achievement. However, the influence of many other variables could not be weeded out particularly the quality-of-teaching variable. Scientific aptitude is also an important variable that could have also been kept constant.

The above mentioned result is consistent with the results reported in many studies. For example, Cohen (1978) and Cross (1977) (as cited in Efiong, n.d.) studied the relationship between academic success and learning styles of field dependence-independence. According to the results of their study, field independent individuals often perform better in school than their field dependent counterparts, especially in elementary school mathematics. The result of the present study supported Babalola (1979) and Sieben (1974) (as cited in Efiong, n.d.), who found that an individual who possesses trait of field independent learning style is consistently superior in Mathematics. The findings confirmed Goodfellow's (1980) (as cited in Musser, 1998) result, who concluded that passing students were more field independent whereas failing students and students who dropped out of nursing courses were more field dependent. In the same year, Vaidya and Chansky (1980) (as cited in Musser, 1998) found that across grades, field independence was correlated with higher mathematics achievement, especially for concepts and their application. This result is also supported by the present study. Later, King (1983) (as cited in Musser, 1998) came to the same conclusion that field independents scored better on music reading tasks than field dependents. Dwyer and Moore (1995) (as cited in Altun and Cakan, 2006) found the field independent learners to be superior to field dependent learners on tests measuring different educational objectives. The researchers concluded that cognitive style had a significant association with students' academic achievement, the present study confirmed these results.

Similarly, Chaudhry (2004), in his study, also found significant relationship between the students' learning style preferences and their academic achievements. Since he focused on four learning styles in his study i.e. Mastery Learners (ST), Interpersonal Learners (SF), Understanding Learners (NT) and Self-Expressive Learners (NF); he concluded that the Mastery and Understanding Learners were generally the higher in their academic achievements than that of the Interpersonal and Self-Expressive Learners. These results, too, are supported by the present study. Tinajero and Paramo (1997) (as cited in Altun and Cakan, 2006) studied the relationship between cognitive styles and student achievement in several subject domains. The researchers asserted that field independent subjects outperformed their field dependent counterparts. In another study, Murphy, Casey, Day, and Young (1997) (as cited in Altun and Cakan, 2006) sought to determine the relationship between academic achievement and cognitive style. They found that field independent students performed better than field dependent subjects only on one of the technical courses. The present study has supported both these results. However, the present study did not verify the results presented in the study of Altun 
and Cakan (2006) who revealed insignificant correlation between participants' academic achievement and their cognitive styles.

\section{Practical Implications}

Teachers, after knowing that individuals have different strengths and are likely to perform very differently according to the nature of their cognitive styles, can help learners realize that there is more than one way to approach and solve a learning problem, and that one approach is almost certainly as valid as another if it leads to the required outcome or achievement. Teachers may also help students build their skills in both their preferred and less preferred modes of learning based on their cognitive styles.

Field independent learners do not value working together, therefore, teachers may encourage them to work in groups and teach them the value of working together, for the sake of achieving group goals, which field dependent students bring into the class room by virtue of their characteristics, i.e. they know the value of sharing and are group-oriented. The teachers can motivate field dependent learners for learning through verbal praise, showing their task's value to other people, external rewards (stars, stickers, prizes), and through providing outlines and structure. Also, the teachers can motivate field independent learners through grades, competitions, choice of activities, and freedom to design their own structure.

In future, this study may be replicated to find out the relationship between cognitive style and academic achievement by keeping important variables constant, other than those which were kept constant in the present study e.g. intelligence of the students, quality of teaching, scientific aptitude etc. Moreover, the present study included only the subject of science. A more comprehensive study including the other subjects, particularly mathematics, will contribute to the understanding of the relationship between cognitive styles and academic achievement in a variety of subject areas.

Replication is needed for any scientific finding in different settings with diverse populations to generalize the results, therefore, similar studies be carried out on the children of various private schools.

\section{REFERENCES}

Acharya, C. (2002). Students' Learning Styles and their Implications for Teachers. Learning Styles, 5(6). Retrieved September 05, 2005, from http://www.cdtl.nus.edu.sg/brief/v5n6/default.htm\#TOP.

Altun, A., and Cakan, M. (2006). Undergraduate Students' Academic Achievement, Field Dependent/Independent Cognitive Styles and Attitude toward Computers. Educational Technology and Society, 9 (1), 289-297.

Centre for Educational and Vocational Guidance (1971). The Scholastic Aptitude Test No.2 for Class $6^{\text {th }}, 7^{\text {th }}, 8^{\text {th }}$. Institute of Education and Research, Lahore: University of the Punjab. 
Chaudhry, M. I. (2004). An Investigation of Students' Learning Styles. Unpublished M.Phil thesis, National Institute of Psychology, Quaid-i-Azam University, Islamabad, Pakistan.

Child, D. (1993). Psychology and the Teacher (5th ed.). London: Cassell.

Crowl, T. et al. (1997). Educational Psychology Windows on Teaching. Madison: Brown and Benchmark Publishers.

Dembo, M. H. (1994). Applying Educational Psychology (5th ed.). New York: Longman.

Efiong E. A. (n.d.). Relationship Between Teachers' Teaching Methods and the Pupils' Learning Styles: A Case Study of Some Primary Schools in Zaria and Soba Local Government Areas in Kaduna State. Retrieved December 21, 2008 from http://www. cvgs.k12.va.us/RESEARCH/PAPER/apa/In-Text.html.

Garrett, H. E. (2000). Statistics in Psychology and Education. NBF Third Reprint. Islamabad: Manza Printing Corporation.

Garrett, H. E. (2006). Statistics in Psychology and Education. New Delhi: Cosmo Publications.

Hansen, J. W. (1995). Student Cognitive Styles in Postsecondary Technology Programs. Online Journal of Technology Education, 6(2). Retrieved December 15, 2008 from http://scholar.lib.vt.edu/ejournals/JTE/jte-v6n2/pdf/ hansena.pdf.

Irvine, J. J., and York, D. E. (1995). Learning Styles and Culturally Diverse Students: A Literature Review. In James A. Banks(ed.) Hand Book of Research on Multicultural Education. New York: Simon and Schuster Macmillan.

Kubiszyn, T., and Borich, G. (2003). Educational Testing and Measurement Classroom Application and Practices. ( $7^{\text {th }}$ ed.). Singapore: John Wiley and Sons, INC.

Liu, Y., and Ginther, D. (1999). Cognitive Styles and Distance Education. Online Journal of Distance Learning and Administration, 2 (111).

Lu, C., and Suen, H. (1995). Assessment Approaches and Cognitive Styles. Journal of Educational Measurement, 32, 1-17. Retrieved November 9, 2008 from http://www. personal.psu.edu/txm4/paper1.html.

Mariani, L. (1996). Investigating Learning Styles. Perspectives. A Journal of TESOL- Italy21(2)/22(1). Retrieved September 05, 2005, from www.Google.com.

Mumford, D. B., and Mohsina Mirza. (2001). Socio-Economic Scales for Pakistan: Measuring the Correlates of Psychiatric Morbidity. (Version 2.1). Unpublished Scale Presented at a PPS Conference, Bristol, UK. 
Musser, T. (1998). Individual Differences: How Field Dependence-Independence Affects Learners. Retrieved November 9, 2008 from http://www. personal.psu.edu/txm4/ paper1.html.

Oltman, P. K., Raskin, E., and Witkin, H. A. (1971). The Group Embedded Figures Test. California: Consulting Psychologists Press, INC.

Ormrod, J. E. (1998). Educational Psychology Developing Learners. New Jersey: Prentice Hall.

Riding, R., and Cheema, I. (1991). Cognitive Styles - an Overview and Integration. Educational Psychology, 11(3-4), 193-215.

Runder, L. M., and Schafer, W. D. (2000). How High Should Reliability Be? ERIC

Clearinghouse on Assessment and Evaluation College Park MD. (ERIC Identifier: ED458213). Retrieved December, 1, 2008, from http://testing.wisc.edu/ Reliability.pdf.

Safdar, M. (2002). A Study of Cognitive Learning Style Field-Dependence/Field-Independence in the Secondary School Physics Laboratories. Unpublished M.Phil thesis, Faculty of Education, Allama Iqbal Open University, Islamabad, Pakistan.

Vasquez, J. (1991). Difference is not Deficiency. Learning Revolution, (IC \#27). Retrieved September 10, 2005, from URL:http://www.context.org/ICLIB/ IC27/ vasquez.htm.

Wells, C.S., and Wollack, J.A. (n.d.). Reliability Coefficient for Internal Consistency. An Instructor's Guide to Understanding Test Reliability. Testing and Evaluation Services. University of Wisconsin. Retrieved December 1, 2008, from http://testing.wisc.edu/ reliability.pdf.

Witkin, H.A. et al. (1971). A Manual for the Embedded Figures Tests. California: Consulting Psychologists Press, INC.

Woolfolk, A. (2004). Educational Psychology (9th ed.). Singapore: Pearson Education, Inc. 